\title{
Investigation and Analysis on the Participation in Sports and Fitness Activities of Teachers in the Yimeng Mountain Area
}

\author{
Yin Yiwei \\ PhD candidate at Air Force Engineering University, Xian 710000, China, lecturer at Yibin University, \\ Yibin 644000, China \\ yinyiwei427@sina.com
}

Keywords: Yimeng Mountain Area, Ordinary Teachers, Sports Fitness, Survey.

\begin{abstract}
Yimeng mountain area of ordinary teachers as the research object of this research, through the literature material law, questionnaire, interview method and mathematical statistics research methods, such as the Yimeng mountain area teachers about fitness and health problems for research. Learn about their sports fitness present situation, and provide a feasible plan, will help to further improve the health of the Yimeng mountain area teachers for the head of the sports department of Linyi public sports policies for reference, for scientifically guiding physical fitness activities to provide related basis.
\end{abstract}

\section{Introduction}

Based on documentation, questionnaires, interviews and mathematical statistics, this paper investigates sports and health related problems of ordinary teachers in the Yimeng Mountain area, grasping the current status of their participation in sports and fitness activities and providing feasible solutions. It is conducive to further improving the health of teachers in the Yimeng Mountain area, providing a reference for the sports administration to make policies on the public sports.

\section{Yimeng Teachers' Perception on Healthiness}

The World Health Organization defines health as "a state of complete physical, mental and social well-being and not merely the absence of disease or infirmity"(YuTao (2009), Wu Xiangzhi et al. (2012), Drenowatz Clemens et al.(2014), Drenowatz Clemens et al(2013),Alison Wrench et al.(2015)). The majority of teachers perceive healthiness from a biological perspective and this paper surveys the notion that healthiness can be judged by the presence or absence of diseases. Of the teachers surveyed by the author (see chart 1), 18.6\% regard as true the notion that the absence of diseases means healthiness, $36.7 \%$ are not sure whether this notion is true or not and only $44.7 \%$ believe it is not correct. This result demonstrates that most teachers possess a comprehensive perception on healthiness. However, it can be inferred that a large number of teachers' perception on healthiness is still blurred and as many as $18.6 \%$ think the notion that the absence of diseases means healthiness is correct.

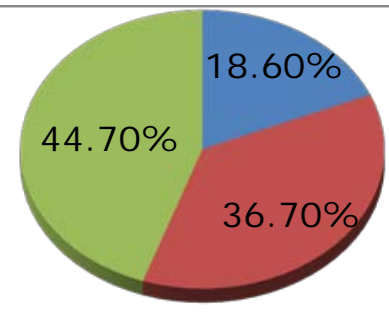

- Absence of diseases means healthiness

- Unsure

Absence of diseases doesn't mean healthiness

Chart 1: Survey on the notion that healthiness can be judged by the presence or absence of diseases 


\section{Yimeng Teachers' Needs and Motives for Fitness Activities}

Chart 2: Needs of fitness activities of teachers at different age stages (\%)

\begin{tabular}{|c|c|c|c|c|c|c|}
\hline Age & $<25$ & $26-35$ & $36-45$ & $46-55$ & $>56$ & Total \\
\hline Important & 65.8 & 51.3 & 54.2 & 78.4 & 88.2 & 70.8 \\
\hline Dispensable & 19.8 & 27.6 & 25.4 & 12.3 & 5.1 & 23.5 \\
\hline Unimportant & 14.4 & 21.1 & 20.4 & 9.3 & 6.7 & 5.7 \\
\hline
\end{tabular}

\subsection{Needs of fitness activities}

As shown in Chart 2, 70.8\% of the Yimeng teachers surveyed in this paper think that it is necessary for them and their families to participate in fitness activities; as many as $23.5 \%$ think it is dispensable and 5.7\% think it isn't necessary. Most teachers regard fitness activities as necessary, but because of the hindrance of actual conditions and the lack of awareness of public fitness, there is a rather long way to go if the needs of fitness activities should be met. According to Chart 2, teachers' needs fitness activities are quite different, showing a V-shaped trend. That is to say, the number of teachers younger than 25 and older than 46 is larger than that of other age stages. The fact that teachers younger than 25 have more needs for fitness activities might have resulted from their interest in sports and the personality of being active. The fact that teacher older than 46 needs fitness activities might have resulted from their pursuit of a healthy elderly life. Teachers in-between need fewer fitness activities, either because they are healthy and strong, or because affairs of work and family prevent them from participating fitness activities(Zahner Lukas et al.(2009), Oja Pekka et al.(2015), Perrier Marie-Josée et al.(2015), Dominic Malcolm(2014), Rosie Meek et al.(2012)).

3.2 Main Motives for Participating Fitness Activities

Chart 3: Yimeng teachers' motives for participating sports and fitness activities

\begin{tabular}{|c|c|c|c|c|c|c|}
\hline $\mathrm{X}$ & $<25$ & $26-35$ & $36-45$ & $46-55$ & $>56$ & Total \\
\hline Motives for fitness & $(\mathrm{n}=206)$ & $(\mathrm{n}=638)$ & $(\mathrm{n}=462)$ & $(\mathrm{n}=178)$ & $(\mathrm{n}=40)$ & $(\mathrm{n}=1524)$ \\
\hline Recreation & 19.2 & 15.1 & 15.8 & 16.2 & 17.6 & 16.1 \\
\hline Improving Health & 18.4 & 18.2 & 17.0 & 20.4 & 22.3 & 18.2 \\
\hline Body-building & 16.6 & 14.4 & 13.4 & 13.2 & 5.6 & 14.0 \\
\hline Promoting social relations & 15.6 & 15.8 & 18.3 & 20.5 & 9.6 & 16.9 \\
\hline Becoming more athletic & 11.2 & 14.3 & 14.8 & 10.3 & 14.7 & 13.6 \\
\hline Adjusting moods & 11.8 & 11.9 & 11.5 & 9.3 & 13.9 & 11.5 \\
\hline Curing diseases & 7.2 & 10.3 & 9.2 & 10.1 & 16.3 & 9.7 \\
\hline
\end{tabular}

Having surveyed and analyzed Yimeng teachers' seven motives for participating fitness activities, the paper finds that, as shown in chart 3, these motives can be ranked according to their frequencies: $18.2 \%$ of the teacher surveyed choose health improving as their first motive, among which teachers older than 46,especially those older than 56, are of a higher proportion than teachers at other age stages, and this is because older teachers pay more attention to their health condition than younger teachers do to theirs. The motives of recreation and promoting social relations account for $16.1 \%$ and $16.9 \%$ respectively, and this has a direct connection with their life and work stress, which can be relieved through recreation and social relation promotion. The motive of body-building, and in turn decreasing the incidence of hypertension and cardiovascular and cerebrovascular diseases, accounts for $14.0 \%$. The motive of improving athletic ability and physical attributes such as strength, flexibility and stamina through sports activities accounts for $13.6 \%$ and the motives of adjusting moods and curing diseases account for $11.5 \%$ and $9.7 \%$ respectively. It can be seen from the chart that as the age increases the proportion of choosing the motive of curing diseases rises evidently and the proportion of choosing the body-building decreases obviously. When comparing the motives of male and female teachers, we can find that, although they share the motive of improving health and enjoying the pleasure of sports, more female teachers choose the motive of body-building than male ones do and the needs of developing character and adjusting moods through sports are higher among 
male teachers than female one(Casey MeghanM et al.(2007), S. Jang et al.(2012), J. Schiffer(1976), Marta Castañer et al.(2013)).

\section{Health Conditions of Yimeng Teachers}

Chart 4: Health conditions of Yimeng teachers participating in fitness activities

\begin{tabular}{|c|c|c|c|c|c|c|}
\hline Age & $<25$ & $26-35$ & $36-45$ & $46-55$ & $>56$ & Total \\
\hline Health conditions & $(\mathrm{n}=206)$ & $(\mathrm{n}=638)$ & $(\mathrm{n}=462)$ & $(\mathrm{n}=178)$ & $(\mathrm{n}=40)$ & $(\mathrm{n}=1524)$ \\
\hline Healthy & 28.1 & 26.8 & 25.0 & 23.8 & 20.2 & 25.9 \\
\hline Generally healthy & 30.3 & 32.1 & 28.9 & 27.6 & 31.2 & 30.3 \\
\hline Sometimes ill & 33.3 & 35.2 & 43.5 & 36.1 & 34.8 & 37.6 \\
\hline Weak and frail & 8.3 & 5.9 & 2.6 & 12.5 & 13.8 & 6.2 \\
\hline
\end{tabular}

As shown from the statistics in chart 4, teachers in the Yimeng Mountain area are confident of their own health cinditions. $25.9 \%$ of the teachers think they themselves are healthy, while $36.2 \%$ of the teachers think that they are sometimes ill. Viewed from the distribution of ages, the number of teachers regarding themselves as healthy declines as the age increases, decreasing from $28.1 \%$ of the age stage of younger than 25 to $20.2 \%$ of the age stage of older than 56 . The result above shows that the health of some of the Yimeng teachers is influenced by internal and outter factors. Subjectively, they are not healthy, factors such as self-conciousness, intelligence, emotions and wills leading to an unbalanced mood, even to a psychological disorder. Bad habits in the daily life such as not having breakfeast, unbalanced food sturcture, irregular sleep and rise, smoking, drinking, and lack of sports exercises might also lead to a sub-healthy condition for teachers(Jiang Bo et al.(2013))

\section{Sports Events Participated in by Yimeng Teachers}

Chart 5: Number and proportion of Yimeng teachers participating in different sports events

\begin{tabular}{|c|c|c|c|c|c|}
\hline & $\begin{array}{c}\text { Track } \\
\text { events }\end{array}$ & $\begin{array}{c}\text { Ball } \\
\text { events }\end{array}$ & $\begin{array}{c}\text { Gymnastic and dancing } \\
\text { events }\end{array}$ & $\begin{array}{c}\text { Traditional ethnic } \\
\text { sports events }\end{array}$ & Others \\
\hline Number & 686 & 543 & 189 & 94 & 12 \\
\hline Percentage & 45.0 & 35.6 & 12.4 & 6.2 & 0.9 \\
\hline Male(\%) & 43.0 & 43.6 & 1.3 & 11.1 & 1.0 \\
\hline Female(\%) & 41.8 & 25.3 & 20.2 & 10.2 & 2.5 \\
\hline
\end{tabular}

As shown in chart 5, teachers in the Yimeng area mainly participate in the track and the ball events, respectively accounting for $45.0 \%$ and $35.6 \%$. Apart from gymnastica and dancing events, female and male teachers show little difference in other events. The reason for this might be that female teachers like the more recreational and graceful aerobics and dance, which is decided by their biological and psychological features. According to the survey, primary and middle school teachers in the Yimeng Mountain area who are younger than 25 account forthe highest of 52.4\%, among which the number participating in track events rises with the increase of age, with teachers older than 56 taking up the highest of $71.4 \%$ and teachers younger than 25 accounting for only $40.1 \%$. Among the teachers choosing traditional ethnic sports, the age stage older than 56 is higher than any other age stages.

\section{Frequency and Duration of Yimeng Teachers' Paticipation in Fitness Activities}

Chart 6: Survey on frequency and duration of Yimeng teachers'participation in fitness activities

\begin{tabular}{|c|c|c|c|c|c|c|}
\hline Age & $<25$ & $26-35$ & $36-45$ & $46-55$ & $>56$ & Total \\
\hline Frequency and duration & $(\mathrm{n}=206)$ & $(\mathrm{n}=638)$ & $(\mathrm{n}=462)$ & $(\mathrm{n}=178)$ & $(\mathrm{n}=40)$ & $(\mathrm{n}=1524)$ \\
\hline Once a week & 29.3 & 57.6 & 54.3 & 30.5 & 27.4 & 48.9 \\
\hline Twice a week & 42.1 & 25.8 & 27.6 & 38.4 & 34.2 & 30.2 \\
\hline Three times or more a week & 28.6 & 16.6 & 18.1 & 31.1 & 38.4 & 20.9 \\
\hline
\end{tabular}




\begin{tabular}{|c|c|c|c|c|c|c|}
\hline$<30 m i n$ once & 42.6 & 42.2 & 43.5 & 37.6 & 22.8 & 41.6 \\
\hline 30--60min once & 34.2 & 39.7 & 40.9 & 38.5 & 37.8 & 39.1 \\
\hline$>60 m i n$ once & 23.2 & 18.1 & 15.6 & 23.9 & 39.4 & 19.3 \\
\hline
\end{tabular}

As shown by the statistics in chart 6, 20.9\% of the teachers surveyed in this research particapate in sports activities three times a week and only 19.3\% enjoy a paticipation duration longer than 60 minutes. According to the statistics of the United Kingdom Sports Council in 1992, 41\% of the female citizens participated in sports activities three times a week, each time lasting for over 30 minutes, and the figure for male Canadian citizens in 1990 was 46\%. In 1994, this indicator for male Finlanders was 31\% (35\% for female Finlanders). It can be seen that developed countries in the world enjoy a higher proportion of population participating in sports activities three times a week than China does. That is to say, the proportiong of teachers in the Yimeng Mountain area paricipating in sports activities is quite low and the situation of sports participation is not optimistic. As shown in the chart, teachers aged between 46 and 55, especially those older than 56, are more active in sports participation, because they are about to retire or already retired, with a relatively stable family life and work, and because their reduced stress from various aspects leaves them with more spare time. Besides, as their physicial ability begins to fall, they participate in more sports activities in order to work and live better. Teachers between 26 and 45 are less inclined to participate in sports activities because they undergo a higher stress of work and family life and thus a reduced spare time(Muhammad Sarwar et al.(2014), Da-Fu Huang et al (2014), Subhan Zein(2016)) .

\section{Main Factors Influencing Yimeng Teachers' Participation in Sports Activities}

\subsection{Low Economic Income}

Yimeng teachers' invest in fitness activities is an economic behavior on the basis of generally meeting other needs and there is a positive correlation between personal income and the participation in fitness activities. According to the research, the discrepancy in personal income significantly limits teachers time and facilities of sports participation.Because of a relatively lower income, $25 \%$ of the teachers in rural areas and city-country fringes confine their sports activities in their houses and offices; only $5 \%$ of them participate in sports activities in public gyms and $60 \%$ don't have time to participate in sports activities, while $50 \%$ of the teachers with a higher income in urban and developing areas have time to participate in sports activities. There is an evident discrepancy between rural and urban areas in terms of Yimeng teachers' participation in sports activities, with an increasing number of teachers in cities and rich areas participating in sports activities and a small or even zero number of teachers in rural and less-developed areas participating in sports activities. This discrepancy between regions and economic status has an overall impact on the implementation of the public fitness plan in the Yimeng Mountain area.

\subsection{Lack of Fields and Unreasonable Charges}

Currently, the lack of sports fields and fitness facilities and the over-high charge obstruct teachers' interest in participating in sports activities. According to our analysis, this is on one hand because the government of the agriculture-dominated Yimeng Mountain area, with the largest population in Shandong province and a less-developed economy, invests relative less amount of money in sports, and on the other hand because the increase of sprots fields and facilities could not match the speed of population growth and the increasingly grwoth of people's needs, which in turn hinders people from participating in sports. Moreover, incorrect methods of exercise cannot be redressed and prevented in time, and would easily lead to an opposite result, making some people lose their confidence and interest.

\subsection{Imperfect and Ill-Popularized Physical Education in Schools}

According to our reseach, 28\% of the teachers surveyed acquire their knowledge of physical education from schools, $37 \%$ from mass media like the computer, TV and radio, and $25 \%$ from books and the help of friends. When it comes to the method of keeping fit, most teachers adopt jogging and working as their methods of excercise, which are the simplest and the most rudimentary. The majority of teachers haven't acquired a more sientific and systematic method of working out. The imperfection 
of physical education in schools leads to the less knowledge of fitness acquired by students at an early age, which is a key reason for their unenergetic participation in fitness activities when they grow up. 7.4 Influence of Sport Values on Yimeng Teachers’ Participation in Fitness Activities

According to Dr. Feng Weisheng, “There are various factors influencing sport exercises, but sport values are the subjective factor that decides the activeness of a person's participation in sports, as well as the source of other influencing factors. "Sport values consist of a person's basic understanding and views of sports. Values reflect the bilateral relationship between the subject and the object; they originate in the object's satisfaction of the subject's needs. Sport values are people's basic viewpoints of evaluating and assessing sports from the perspective of their own needs. Since there is still a large gap between the economy, modern culture and lifestyle of the Yimeng Mountain area and those of other developed coastal cities, people's awareness of the value of sports are relatively weak, which has a certain impact on their understanding of and participation in sport activities and directly influences an individual's belief in and pursuit of sports. Media like magazines and newspapers related to teachers seldom or even never mention contents about sport life and fitness activities. This tendency of public opinion restricts teacher's interest in sports as well as the beneficial formation of their value orientation towards sport activities, and in turn influences their enthusiasm for participating in sport activities.

\subsection{Imperfect Implementation of Certain Rules and Regulations on Sports}

Currently, some schools in the Yimeng Mountain area fail to comprehensively implement the constitution, the Sports Law and the Teacher's Law, and isunaware of the significance of teachers' participation in sports. Moreover, there are corresponding regulations to ensure teachers' participation in sports, which has a certain limitation over the promotion of fitness activities among teachers.

It is known to all that the constitution and the Sports Law are basic laws for the development of sports in China. However, some articles in them are still abstract and general. Therefore, in order to carry out law-enforcement activities related to sports more practically by local authorities, there should be corresponding judicial interpretation and enforcement regulation at the national level as soon as possible. Local sport authorities at different levels should formulate administrative regulations on sports in accordance with the local situation so as to better implement sport-related laws.

\section{Conclusion}

Human resources should be fully utilized in accordance with the actual situation of community instructors in the Yimeng Mountain area, so as to vigorously encourage PE teachers in colleges to undertake the part-time role of community PE instructor. By doing so, fitness coaching centres in communities, sub-districts and neighbourhood committees can be established to popularize scientific knowledge and methods of participating in sports and improve the overall level of skills in public fitness activities. All in all, the benefits of participating in sports activities are realized by more and more teachers in the Yimeng Mountain area, but their participation is still limited and influenced by social and personal factors. Therefore, in order to promote sports participation among teachers and efficiently implement the national fitness program, we should correctly instruct and organize by strengthening publicity, creating a good atmosphere for sports, enhancing awareness for and healthy perceptions on sports, and encouraging more teachers to participate in sports activities.

\section{Acknowledgements}

This paper 2017 scientific research projects in Education department of Sichuan province "transformation development under the background of local undergraduate colleges and universities teachers construction research - in Sichuan province, for example" of one of the research results, Scientific research project number: 17 sb0615 


\section{References}

[1] Alison Wrench, Robyne Garrett.2015. PE: it's just me: physically active and healthy teacher bodies. International Journal of Qualitative Studies in Education, Vol.28 (1), pp.72-91. DOI: 10.1080/ 09518398.2013.855342.

[2] Brenda Leibowitz, Vivienne Bozalek, Susan Schalkwyk, Christine Winberg.2015. Institutional context matters: the professional development of academics as teachers in South African higher education. Higher Education, Vol.69 (2), pp.315-330. DOI:10.1007/s10734-014-9777-2.

[3] Casey Meghan M,Payne Warren R,Eime Rochelle M, Brown Sue J.2007. Sustaining health promotion programs within sport and recreation organisations. Journal of Science and Medicine in Sport, Vol.12 (1), pp.113-8. DOI: 10.1016/j.jsams.2007.08.007.

[3] DrenowatzClemens,Kobel Susanne, KettnerSarah,Kesztyüs Dorothea, Steinacker Jürgen M.2014. Interaction of sedentary behaviour, sports participation and fitnes with weight status in elementary school children.European journal of sport science, Vol.14 (1), pp.100-5. DOI: 10.1080/ 17461391.2012.732615.

[4] Drenowatz Clemens, Steine rRonaldP, Brandstetter Susanne, KlenkJochen, Wabitsch Martin, Steinacker Jürgen M.2013. Organized sports, overweight, and physical fitness in primary school children in Germany. Journal of obesity, Vol.2013, pp.935245. DOI: 10.1155/2013/935245.

[5] Dominic Malcolm.2014. Sport, health and medicine: a sociological agenda. Asia Pacific Journal of Sport and Social Science, Vol.3 (1), pp.51-63.DOI: 10.1080/21640599.2014.889343.

[6] Da-Fu Huang, Michael Singh.2014. Critical perspectives on testing teaching: reframing teacher education for English medium instruction. Asia-Pacific Journal of Teacher Education, Vol.42 (4), pp.363-378. DOI: 10.1080/1359866X.2014.956046.

[7] J. Schiffer.1976. Sport und Gesundheit aus der Sichteines Soziologen. Sozial- und Pr? ventivmedizin SPM, Vol.21 (6). DOI: 10.1007/BF02102156.

[8] Jiang Bo, Chang Jindong, Sun Yiwen.2013. Empirical Research on Professional Moral Cultivation of P.E. Teachers in Universities. Chinese Studies, Vol.02 (03), pp.134-138. DOI: 10.4236/ chnstd. 2013.23021

[9] Kay Owens.2015. Changing the teaching of mathematics for improved Indigenous education in a rural Australian city. Journal of Mathematics Teacher Education, Vol.18 (1), pp.53-78.DOI: 10.1007/ s10857-014-9271-X.

[10] Muhammad Sarwar, Muhammad Alam, Shafqat Hussain, Ashfaque Ahmad Shah, Mehlah Jabeen.2014. Assessing English speaking skills of prospective teachers at entry and graduation level in teacher education program. Language Testing in Asia, Vol.4 (1), pp.1-9.DOI: 10.1186/ 22290443-4-5.

[11] Murphy Michelle R., Marshall Kathleen J.2015. Common Core Preparation in Special Education Teacher Education Programs. Teacher Education and Special Education: The Journal of the Teacher Education Division ofthe Council for Exceptional Children, Vol.38 (3), pp. 167-185. DOI: 10.1177/0888406415577453.

[12] Martin Schmeiser.2007. Zu den Soziologieanteilen in einem „Bachelor / Master of Arts in Education“ an einer Pädagogischen Hochschule. Soziologie, Vol.36 (2), pp.171-185. DOI: 10.1007/s11617-007-0005-7.

[13] Marta Castañer,Oleguer Camerino,M. Teresa Anguera, Gudberg K. Jonsson.2013. Kinesics and proxemics communication of expert and novice PE teachers. Quality \& Quantity, Vol.47 (4), pp.1813-1829. DOI: 10.1007/s11135-011-9628-5. 
[14] OjaPekka,TitzeSylvia, KokkoSami,Kujala Urho M, HeinonenAri, KellyPaul, KoskiPasi,Foster Charlie.2015. Health benefits of different sport disciplines for adults: systematic review of observational and intervention studies with meta-analysis. British journal of sports medicine, Vol.49 (7), pp.434-40. DOI: 10.1136/bjsports-2014-093885.

[15] Perrier Marie-Josée, Shirazipour Celina H,Latimer-Cheung Amy E.2015. Sport participation among individuals with acquired physical disabilities: group differences on demographic, disability, and Health Action Process Approach constructs. Disability and health journal, Vol.8 (2), pp.216-22. DOI: 10.1016/j.dhjo.2014.09.009.

[16] Rosie Meek,Gwen Lewis.2012. The role of sport in promoting prisoner health. International Journal of Prisoner Health, Vol.8 (3), pp.117-130. DOI: 10.1108/17449201211284996.

[17] S. Jang, K. Liller, B. Morris, J. Konin, S. Wong.2012. Data analysis of the smart sports injury registry for high school athletes. Injury Prevention, Vol.18 (Supplement), pp.A129-A129. DOI: 10.1136/injuryprev-2012-040590g.1.

[18] Subhan Zein.2016. Pre-service education for primary school English teachers in Indonesia: policy implications. Asia Pacific Journal of Education, Vol.36 (sup1), pp.119-134. DOI: 10.1080/ 02188791.2014.961899.

[19] Serap Sevimli-Celik, James E. Johnson.2016.Teacher preparation for movement education: increasing pre-service teachers' competence for working with young children. Asia-Pacific Journal of Teacher Education, Vol.44 (3), pp.274-288. DOI: 10.1080/1359866X.2015.1079303. 